University of Nebraska - Lincoln

DigitalCommons@University of Nebraska - Lincoln

Faculty Publications: Department of

Entomology

Entomology, Department of

$9-2001$

\title{
Eicosanoids act in nodulation reactions to bacterial infections in newly emerged adult honey bees, Apis mellifera, but not in older foragers
}

Jon C. Bedick

University of Nebraska-Lincoln, jbedick@shawnee.edu

Hasan Tunaz

University of Nebraska-Lincoln

A. R. Nor Aliza

University of Nebraska-Lincoln

Sean Putnam

University of Nebraska-Lincoln, sputnam@lps.org

Marion D. Ellis

University of Nebraska-Lincoln, mellis3@unl.edu

See next page for additional authors

Follow this and additional works at: https://digitalcommons.unl.edu/entomologyfacpub

Part of the Entomology Commons

Bedick, Jon C.; Tunaz, Hasan; Nor Aliza, A. R.; Putnam, Sean; Ellis, Marion D.; and Stanley, David W., "Eicosanoids act in nodulation reactions to bacterial infections in newly emerged adult honey bees, Apis mellifera, but not in older foragers" (2001). Faculty Publications: Department of Entomology. 187.

https://digitalcommons.unl.edu/entomologyfacpub/187

This Article is brought to you for free and open access by the Entomology, Department of at DigitalCommons@University of Nebraska - Lincoln. It has been accepted for inclusion in Faculty Publications: Department of Entomology by an authorized administrator of DigitalCommons@University of Nebraska - Lincoln. 


\section{Authors}

Jon C. Bedick, Hasan Tunaz, A. R. Nor Aliza, Sean Putnam, Marion D. Ellis, and David W. Stanley 
Published in Comparative Biochemistry and Physiology Part C: Toxicology \& Pharmacology 130:1 (September 2001), pp. 107-117; doi: 10.1016/S1532-0456(01)00226-5 Copyright ( $\odot 2001$ Elsevier Science Inc. Used by permission.

Submitted May 8, 2001; revised June 13, 2001; accepted June 26, 2001; published online August 30, 2001.

\title{
Eicosanoids act in nodulation reactions to bacterial infections in newly emerged adult honey bees, Apis mellifera, but not in older foragers
}

\author{
Jon C. Bedick, ${ }^{1}$ Hasan Tunaz, ${ }^{1}$ A. R. Nor Aliza, ${ }^{1}$ \\ Sean M. Putnam, ${ }^{1}$ Marion D. Ellis, ${ }^{2}$ and David W. Stanley ${ }^{1}$ \\ ${ }^{1}$ Insect Biochemical Physiology Laboratory, University of Nebraska-Lincoln, \\ 311 Plant Industry Building, Lincoln, NE 68583-0816, USA \\ 2 Department of Entomology, University of Nebraska-Lincoln, Lincoln, NE, USA \\ Corresponding author - D. W. Stanley, tel 403 472-2123, fax 402 472-4687, email dstanley1@unl.edu
}

\begin{abstract}
Nodulation is the first, and qualitatively predominant, cellular defense reaction to bacterial infections in insects. We tested the hypothesis that eicosanoids also mediate nodulation reactions to bacterial challenge in adults of a social insect, the honey bee, Apis mellifera. Treating newly-emerged experimental bees with the eicosanoid biosynthesis inhibitor, dexamethasone, impaired nodulation reactions to bacterial infections, and the influence of dexamethasone was reversed by treating infected insects with arachidonic acid, an eicosanoid precursor. Several other eicosanoid biosynthesis inhibitors, including the cyclooxygenase inhibitor, indomethacin, and the dual cyclooxygenase/lipoxygenase inhibitor, phenidone, also impaired the ability of experimental honeybees to form nodules in reaction to bacterial challenge. The influence of phenidone on nodulation was expressed in a dose-dependent manner. However, in experiments with older honey bees foragers, similar bacterial challenge did not evoke nodulation reactions. We infer from our results that while eicosanoids mediate cellular immune responses to bacterial infections in newly emerged honey bees, and more broadly, in most insect species, nodulation reactions to bacterial challenge probably do not occur in all phases of insect life cycles.
\end{abstract}

Keywords: eicosanoids, bacterial infection, insect immunity, honey bees

\section{Introduction}

Hemocytic immune reactions to bacterial infections involve direct cellular interactions between circulating hemocytes and bacteria. Specific cellular defense mechanisms include phagocytosis and nodulation
(Gupta, 1991). While humoral and hemocytic immune reactions to bacterial infections are well documented, until recently, when there was virtually no information on the biochemical events responsible for mediating insect immune reactions. Drawing on the background of signal transduction systems in mammalian 
immunity, Stanley-Samuelson et al. (1991) suggested insect cellular immune reactions are mediated by eicosanoids. Eicosanoids are oxygenated metabolites of arachidonic acid and two other polyunsaturated fatty acids ( Figure 1), the structures and biosynthesis of which are outlined elsewhere (Stanley, 2000). Eicosanoids are very well understood in the contexts of human and animal medicine, where they influence many pathophysiological events, including inflammation. Beyond their actions in mammals, recognition of the biological significance of eicosanoids in invertebrates is steadily growing, as detailed in recent reviews ( Stanley and Howard, 1998; Howard and Stanley, 1999; Stanley, 2000).

Figure 1. An overview of 20:4n-6 metabolism as understood from mammalian physiology. Three polyunsaturated fatty acids, 20:3n-6, 20:4n-6 and 20:5n-3 are potential substrates for eicosanoid biosynthesis. Of these, metabolism of $20: 4 n-6$ is most well studied. Chemical structures are denoted by numerals. 1=a cellular phospholipid; 2=hydrolyzed 20:4n-6; 3=prostaglandin $E_{2} ;$ 4=5-hydroperoxyeicosatetraenoic acid; 5=leukotriene $\mathrm{B}_{4} ; \mathbf{6}=11$,12-epoxyeicosatrienoic acid; and 7=lipoxin A. Capital letters indicate major enzyme systems responsible for eicosanoid biosynthesis. $A=$ phospholipase $A_{2}$; $\mathrm{B}=$ cyclooxygenase and associated enzyme steps; $\mathrm{C}=$ cytochrome $\mathrm{P}_{450}$ epoxygenase; and $\mathrm{D}=$ lipoxygenase.

In our initial investigations into the possible roles of eicosanoids in invertebrate immunity, we determined that treating tobacco hornworms, Manduca sexta, with pharmaceutical inhibitors of eicosanoid biosynthesis rendered experimental hornworms unable to clear bacterial infections from hemolymph circulation. We inferred from these observations that some or all of the cellular defense reactions responsible for clearing bacterial infections from hemolymph are mediated by eicosanoids (Stanley-Samuelson et al., 1991). This was the first suggestion of a signal transduction system in invertebrate cellular immunity.

Nodulation is an insect cellular defense reaction responsible for clearing large numbers of bacterial cells from circulation during the first $2 \mathrm{~h}$ of an infection (Horohov and Dunn, 1983). Because nodulation is the predominant cellular reaction to bacterial infections, we hypothesized that eicosanoids mediate nodulation reactions to bacterial infections. We tested this idea by injecting hornworms with an eicosanoid biosynthesis inhibitor, then infecting them with bacteria. Compared to ethanol-treated controls, the experimental larvae produced significantly fewer nodules in response to similar bacterial challenges. Moreover, the influence of the eicosanoid biosynthesis inhibitor, dexamethasone, could be reversed by treating the experimental larvae with arachidonic acid, the immediate precursor of eicosanoids. These findings supported the idea that nodulation is one of the cellular immune responses to bacterial infections that is mediated by eicosanoids (Miller et al., 1994).

On the basis of these findings in a single lepidopteran species, we developed the hypothesis that eicosanoids mediate nodulation reactions to bacterial infections in most, if not all, insect species, which for convenience we refer to as the eicosanoid hypothesis (Stanley and Howard, 1998; Stanley, 2000). Using similar experimental protocols, we have obtained comparable results with several insect species, including the tenebrionid beetle, Zophobas atratus (Miller et al., 1996), the silkworm, Bombyx mori (Stanley-Samuelson et al., 1997) the larvae of two other moths, black cutworms, Agrotis ipsilon and true armyworms, Pseudaletia unipuncta (Jurenka et al., 1997), adults of the cricket, Gryllus assimilis (Miller et al., 1999), the cockroach, Periplaneta americana (Tunaz and Stanley, 1999) and the 17-year periodical cicadas, Magicicada septendecim and M. cassini (Tunaz et al., 1999). In related work, Mandato et al. (1997) found that cell spreading and prophenoloxidase activation, two distinct phases of nodulation, as well as another cellular defense reaction, phagocytosis, also are mediated by eicosanoids in waxmoths, Galleria mellonella. These findings uniformly support the eicosanoid hypothesis.

Such positive support notwithstanding, innate immunity can be regarded as an adaptive trait whose expression is linked to life-history (Dunn, 1990). Under this view, there remains the question of whether all insects are competent to mount cellular defense reactions. In this paper we report on experiments designed to test the eicosanoid hypothesis in a social insect, the honey bee, Apis mellifera. We observed nodulation reactions to bacterial infections in newly-emerged adults, and found that these reactions depend on eicosanoid biosynthesis. However, we were unable to record nodulation reactions to bacterial challenge in older adults, those which had reached the age of foragers. We infer that the eicosanoid hypothesis is a useful organizing concept in insect immunity, however, it must be taken within the broader idea that the various expressions of insect immunity are adaptive traits which may or may not be present in any given life-history stage within a species. 


\section{Materials and methods}

\subsection{Organisms}

Honey bees, A. mellifera, were taken from hives maintained on the University of Nebraska, Lincoln, campus during late summer. Pupae were removed from combs and used immediately. Newly-emerged adult bees were taken from combs within $24 \mathrm{~h}$ of emergence. Foraging bees were captured near the entrances of their hives.

Cultures of a pigmented strain of the bacterium Serratia marcescens were taken from the microbe collection at UNL, and nutrient broth (Difco) was purchased from Carolina Biological Supply (Burlington, $\mathrm{NC}$ ). Bacteria were grown in $50 \mathrm{ml}$ of nutrient broth in an environmental shaker at $37^{\circ} \mathrm{C}$ and $100 \mathrm{rev} . / \mathrm{min}$. The bacteria were freeze-dried, and this material was taken up into pyrogen-free water for injection into the bees.

\subsection{Injections and assays for nodulation}

We followed the protocols formalized by Miller and Stanley (1998). Before injections, the bees were chilled, and then surface sterilized by swabbing their cuticle with 95\% ethanol. We injected adults with either the phospholipase $\mathrm{A}_{2}\left(\mathrm{PLA}_{2}\right)$ inhibitor dexamethasone $\{(11 \beta, 16 \alpha)$-9-fluoro-11,17,21-trihydroxy-16-methylpregna-1,4-dione\}, the cyclooxygenase inhibitor indomethacin \{1-P-(chlorobenzyl)-5-methoxy-2-methyl3-indolyl-acetic acid\} or the dual cyclooxygenase and lipoxygenase inhibitor phenidone \{1-phenyl-3-pryazolidinone\} (all inhibitors purchased from BioMol, Plymouth Meeting, PA). In rescue experiments, adults were injected also with arachidonic acid $\{5,8,11,14-$ eicosatetraenoic acid\}, purchased from Sigma Chemical Co. (St. Louis, MO). Control insects were injected with $95 \%$ ethanol. Drugs and control substances were injected into the opposite side of the abdomen using a $10-\mu 1$ Hamilton 701 syringe. All injections of pharmaceuticals were in a standard dosage of $52 \mu \mathrm{g}$ in $4 \mu \mathrm{l}$ of ethanol, except in dose-response experiments. The fatty acids were injected at dosages of $20 \mu \mathrm{g}$ in $2 \mu \mathrm{l}$ ethanol per adult honey bee.

Immediately after the drug injections, bees were challenged by injecting $50 \mu \mathrm{g}$ of freeze-dried bacterial preparation, made up in pyrogen-free water, into each bee, following injection protocols of Miller and Stanley (1998). Bacteria were injected in 10- $\mu 1$ aliquots, using a 26 gauge 0.5 -inch needle attached to a $50-\mu$ syringe (Hamilton, Reno, NV).
We assessed nodulation at selected times post-infection (PI). We anesthetized the bees by chilling them on ice, and then exposed their hemocoels. Melanized, black nodules were counted under a stereo microscope at $60 \times$. The nodules were distinct, and direct counting reliably reflected the extent of the nodulation response to infections (Miller and Stanley, 1998). After the first counting, the alimentary canal was removed. Nodules in the previously unexposed areas and remaining internal tissues were then counted and the two counts were summed.

\subsection{Control experiments}

We conducted control experiments to register the background numbers of nodules in honey bees. To record the nodulation in unchallenged adults, 19 bees were taken from culture at various times in this project. We anesthetized bees on ice for $10 \mathrm{~min}$, then assessed nodulation. To determine the influence of the drug vehicle, ethanol, on nodule formation, four adults were injected with $4 \mu \mathrm{l}$ of ethanol. Nodulation was assessed $4 \mathrm{~h}$ later, following the standard protocol. To assess the effect of the pharmaceutical products on nodulation in unchallenged bees, a standard dosage of phenidone, in $4 \mu \mathrm{l}$ of ethanol was injected into four bees. Nodulation was assessed by standard methods $4 \mathrm{~h}$ later. Finally, we tested the possibility that water or simple wounding could stimulate nodulation by injecting $4 \mu \mathrm{l}$ of water into five honey bees or piercing the integument of four honey bees. Nodulation was assessed by standard methods $4 \mathrm{~h}$ later.

\subsection{Dose-response curve for freeze-dried bacteria}

The freeze-dried bacterial preparation was made up in pyrogen-free water in four concentrations, 5, 10, 25, and $50 \mu \mathrm{g}$ per injection. Newly-emerged honey bees were anesthetized, sterilized and injected as described. Nodulation was assessed $4 \mathrm{~h}$ later.

\subsection{Time course of nodulation: influence of phenidone}

Individuals in two groups of bees were injected with $4 \mu \mathrm{l}$ of ethanol or with $52 \mu \mathrm{g}$ of phenidone in $4 \mu \mathrm{l}$ of ethanol. The bees were immediately injected with bacteria as described. At 1, 2, and 4-h PI, sub-groups of control and experimental insects were anesthetized, and nodulation was assessed. 


\subsection{Dose-response curve for phenidone}

Individuals in four groups of bees were injected with $4 \mu \mathrm{l}$ of ethanol, or $0.52,5.2$, or $52 \mu \mathrm{g}$ of phenidone in $4 \mu \mathrm{l}$ of ethanol, then challenged with a standard solution of freeze-dried bacteria. At 4-h PI, the bees were anesthetized, and nodulation was assessed.

\subsection{Influence of other eicosanoid biosynthesis inhibi- tors on nodulation}

We divided bees into two groups and injected individuals in each group with either the cyclooxygenase inhibitor indomethacin, or the dual cyclooxygenase/ lipoxygenase inhibitor phenidone, in standard dosages of $52 \mu \mathrm{g}$ in $4 \mu \mathrm{l}$ of ethanol. Control insects were injected with $4 \mu \mathrm{l}$ of ethanol. Following injections, the bees were infected with a standard dosage of bacteria as described. At 4-h PI, the bees were anesthetized and nodulation was assessed.

\subsection{Fatty acid rescue experiment}

Individuals in two groups of adult bees were injected with either $4 \mu \mathrm{l}$ of ethanol or $52 \mu \mathrm{g}$ of dexamethasone in $4 \mu \mathrm{l}$ of ethanol and then infected with bacteria as described. Immediately after challenge, the dexamethasone-treated bees were divided into two subgroups. Individuals in one sub-group were treated with $20 \mu \mathrm{g}$ of arachidonic acid in $2 \mu \mathrm{l}$ of ethanol. Another sub-group was treated with $2 \mu \mathrm{l}$ of ethanol to control for the effects of the extra injection on nodulation. At 4-h PI, bees were anesthetized and nodulation assessed.

\subsection{Determining biosynthesis of prostaglandins by abdominal preparations from newly-emerged honey bees}

We investigated eicosanoid biosynthesis by microsomal-enriched preparations of gut-free honey bee bodies. These experiments followed protocols developed for fat body from M. sexta (Stanley-Samuelson and Ogg, 1994). Briefly, tissues prepared from 15 honey bees were mechanically ground using a 1$\mathrm{ml}$ glass homogenizer. The homogenates were sonicated for $40 \mathrm{~s}$ at $30 \mathrm{~W}$ using a VibraCell sonicator (VibraCell, Danbury, CT). This preparation was centrifuged for $10 \mathrm{~min}$ at $735 \times \mathrm{g}$, and the supernatant was centrifuged for another $20 \mathrm{~min}$ at $16000 \times g$, both steps at $4^{\circ} \mathrm{C}$. The $16000 \times g$ supernatants were microsomal-enriched preparations used in all experiments. Protein concentrations in these preparations were determined as described by Stanley-Samuelson and Ogg (1994).

Radioactive arachidonic acid $(5,6,8,9,11,12,14,15$ $\left.\left[{ }^{3} \mathrm{H}\right]-20: 4,60-100 \mathrm{Ci} / \mathrm{mmol}\right)$ was purchased from DuPont. The incubation buffer was $0.05 \mathrm{M} \mathrm{KH}_{2} \mathrm{PO}_{4}, \mathrm{pH}$ 8.0, amended with a standard co-factor cocktail (2.4 $\mathrm{mM}$ reduced glutathione, $0.25 \mathrm{mM}$ hydroquinone and $25 \mu \mathrm{g}$ hemoglobin per reaction). For each PG biosynthesis reaction, $0.4 \mu \mathrm{Ci}$ of labeled arachidonic acid was dispensed into reaction tubes and the solvent was evaporated. The reactions were carried out in $1.0-\mathrm{ml}$ total volume. The experiments were preceded by a 10 -min pre-incubation at $32^{\circ} \mathrm{C}$ with all reaction components, except the protein source. After a 2-min reaction period at $32^{\circ} \mathrm{C}$, the reactions were stopped by addition of $500 \mu l 0.1 \mathrm{~N} \mathrm{HCl}$. Reaction products were extracted from the acidified reaction mixture three times in ethyl acetate. The combined extracts, containing PGs and possibly lipoxygenase products, were evaporated under $\mathrm{N}_{2}$. A mixture of appropriate eicosanoid standards was added to each sample, then samples were applied to thinlayer chromatography plates (described above). The plates were developed and fractions observed as described (Stanley-Samuelson and Ogg, 1994). Bands corresponding in $R_{\mathrm{f}}$ to selected authentic eicosanoid standards and to free fatty acids were transferred to liquid scintillation vials. Radioactivity in each fraction was determined by adding Ecolite scintillation cocktail (ICN Biomedicals, Irvine, CA) and counting on a LKB Wallac 1209 Rackbeta Liquid Scintillation Counter (Pharmacia, Turku, Finland) at 50\% counting efficiency for $\left[{ }^{3} \mathrm{H}\right]$. Eicosanoid biosynthesis was calculated from the liquid scintillation data. In control experiments, microsomal-enriched preparations were heated in boiling water for $15 \mathrm{~min}$ before the experiments, and processed as just described. The results of these control experiments were used to correct values from biosynthesis experiments.

\subsection{Statistical analysis}

Nodulation data were analyzed by analysis of variance in the General Linear Models procedure, and mean comparisons were made using the Least Significant Difference (LSD) test (SAS Institute Inc., 1989). 


\section{Results}

\subsection{Control experiments}

Table 1 displays the results of control experiments. We recorded less than one nodule/bee $(n=19$ honey bees) in untreated insects taken directly from the culture. Injections with water resulted in approximately four nodules/insect, and simple wounding induced virtually no nodulation. Similarly, we observed approximately eight nodules/insect in bees injected with phenidone. Pure ethanol seemed to induce a moderate level of nodulation because we recorded 46 nodules/insect in bees injected with ethanol. By comparison, challenges with standard dosages of the freeze-dried $S$. marcescens, prepared in pyrogenfree water, resulted in approximately 134 nodules per adult.

\subsection{Dose-response curve for S. marcescens}

We recorded increased nodulation with increasing doses of the freeze-dried bacterial preparation, from approximately 10 nodules/insect at the lowest dose to approximately 50 nodules/insect at the highest dose (Figure 2). As a practical matter, these data informed our use of $50 \mu \mathrm{g} /$ insect in subsequent experiments.

Table 1. Outcomes of background control experiments ${ }^{\text {a }}$

\begin{tabular}{lcc}
\hline Treatment & $\begin{array}{c}\text { Number of } \\
\text { individuals }\end{array}$ & $\begin{array}{c}\text { Nodules per bee } \\
\text { (mean } \pm \text { S.E.M.) }\end{array}$ \\
\hline No treatment & 19 & $0.05 \pm 0.05$ \\
Inject EtOH & 4 & $46.2 \pm 12.4$ \\
Inject water & 5 & $3.6 \pm 1.0$ \\
Bacterial challenge & 15 & $133.9 \pm 11.7$ \\
Wound with needle & 4 & $0.2 \pm 0.2$ \\
Inject phenidone & 4 & $7.7 \pm 3.9$ \\
\hline
\end{tabular}

a Newly-emerged honey bees were treated as specified in the left column, and nodulation was assessed at 4-h post-treatment, except for bees taken directly from combs to assess nodulation in untreated individuals. The phenidone was dissolved in $95 \% \mathrm{EtOH}$, and the vehicle control was 95\% EtOH. The bacterial challenge was our standard dosage of freeze-dried bacteria prepared in pyrogen-free water.

\subsection{Time course of nodulation}

The time course of visible nodule formation in two groups of bees, experimentals and controls, is shown in Figure 3. Phenidone-treated adults formed approximately three nodules/insect at 1-h PI, which increased to seven at 2-h PI, and to approximately 11 at $4 \mathrm{~h}$. The ethanol-treated control adults produced 20 nodules at 1-h PI and 32 at 2-h PI. By 4-h PI, the control bees yielded significantly more nodules, approximately 130/insect.

\subsection{Dose-response curve for phenidone}

The influence of phenidone on nodulation in response to bacterial infections was expressed in a dose-dependent manner (Figure 4). Nodulation declined from approximately 130 nodules/bee in ethanol-treated control bees, to approximately 11 nodules/insect in bees treated with the highest phenidone dosage (Figure 4). Intermediate dosages produced intermediate nodulation reactions.

\subsection{Influence of other eicosanoid biosynthesis inhibi- tors on nodulation}

We considered the influence of three pharmaceutical inhibitors of eicosanoid biosynthesis on nodulation in response to bacterial infections (Figure 5). Compared to control (EtOH) bees, all experimental bees exhibited significantly reduced nodulation in response to bacterial infections (LSD, $P<0.05$ ). We obtained significant differences between the influence of phenidone, which severely inhibited nodule formation, and the influences of indomethacin and dexamethasone.

\subsection{Arachidonic acid reversed the influence of dexa- methasone on nodulation}

According to the evidence taken from research in mammalian physiology, dexamethasone, as one of its actions, inhibits eicosanoid biosynthesis through its effect on $\mathrm{PLA}_{2}$. On this idea, injecting the eicosanoid-precursor polyunsaturated fatty acid, arachidonic acid, into dexamethasone-treated infected adults should reverse the effects of dexamethasone on nodulation. We used the following protocol to test this. After injection with dexamethasone, adults were infected with bacteria and then immediately treated 


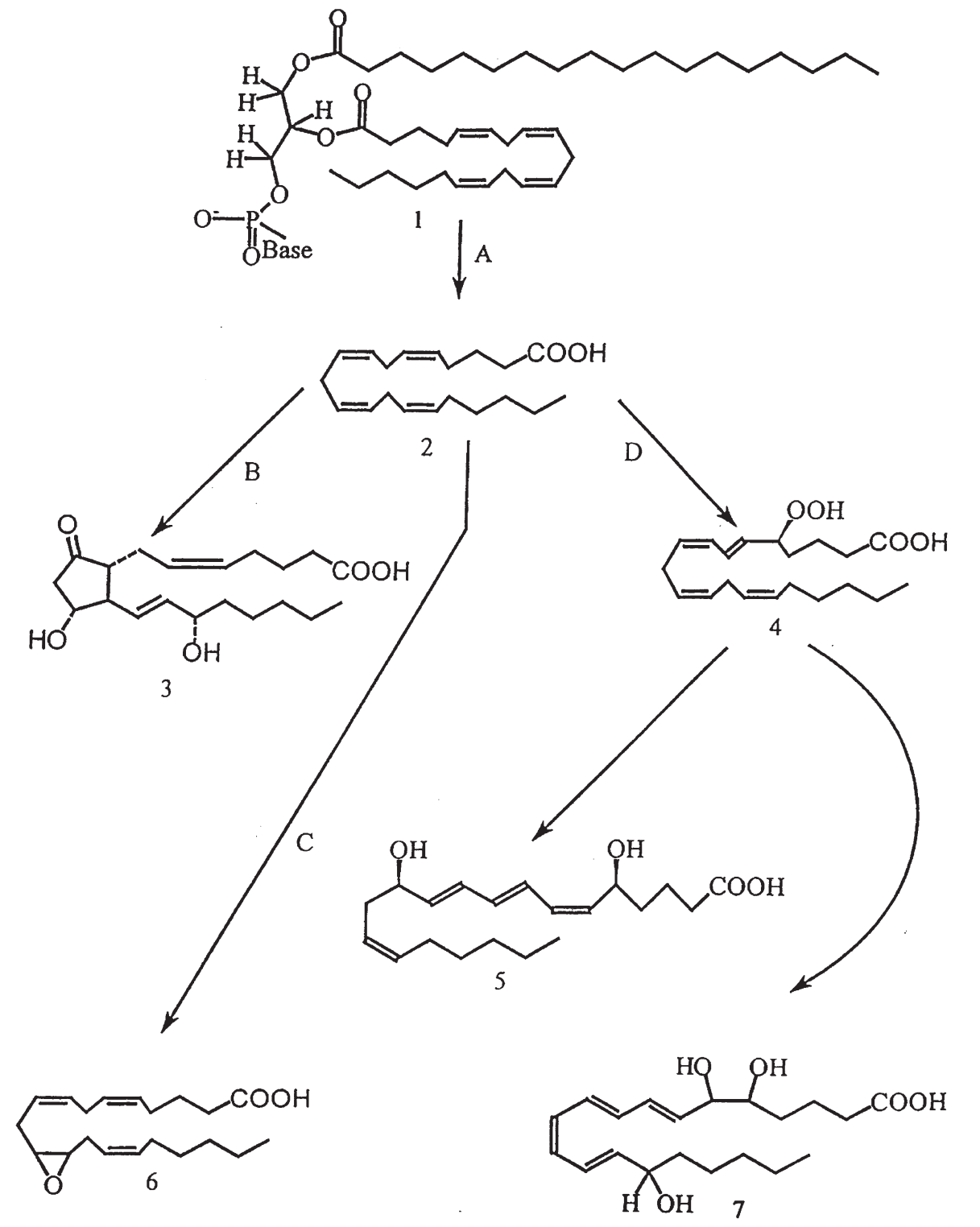

Figure 1. An overview of 20:4n-6 metabolism as understood from mammalian physiology. Three polyunsaturated fatty acids, 20:3n-6, 20:4n-6 and 20:5n-3 are potential substrates for eicosanoid biosynthesis. Of these, metabolism of 20:4n-6 is most well studied. Chemical structures are denoted by numerals. 1 a cellular phospholipid; 2 hydrolyzed 20:4n-6; 3 prostaglandin $E_{2} ; 4$ 5hydroperoxyeicosatetraenoic acid; 5 leukotriene $\mathrm{B}_{4} ; 6$ 11,12-epoxyeicosatrienoic acid; and 7 lipoxin A. Capital letters indicate major enzyme systems responsible for eicosanoid biosynthesis. A phospholipase $\mathrm{A}_{2}$; B cyclooxygenase and associated enzyme steps; C cytochrome $\mathrm{P}_{450}$ epoxygenase; and D lipoxygenase.

with arachidonic acid. To control for the influence of the third injection on nodulation, an additional control group of bees was injected with ethanol. As can be seen in Figure 6, arachidonic acid treatments reversed the effects of dexamethasone on nodulation (LSD, $P<0.05)$. The ethanol-injected control bees yielded approximately 160 nodules/honey bee and dexamethasone-treated bees approximately 37 nodules/honey bee, both in line with expectation. The arachidonic acid-treated bees produced approximately
190 nodules/bee, also in line with expectation for control animals. The second control group, injected with a second dose of ethanol, yielded approximately 50 nodules/bee.

\subsection{The influence of age on nodulation reactions to bacterial challenge}

Newly-emerged honey bees produced high numbers of nodules, usually well over 130 nodules/bee, 
in reaction to our standard challenge. The situation was entirely different for older, foraging honey bees. At $4 \mathrm{~h}$ after injection with our standard bacterial challenge, we recorded no nodules in foragers. This seemed a little odd, compared to our results with younger bees, and we investigated the point a little further. While we were able to withdraw hemolymph and register the presence of hemocytes with younger bees, we were not able to withdraw hemolymph from foragers.

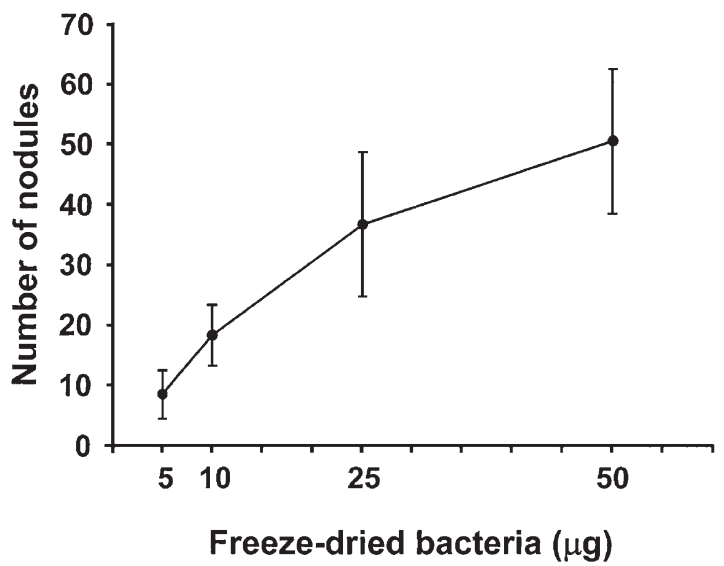

Figure 2. The influence of freeze-dried bacteria, S. marcescens, on nodulation reactions in adult honey bees, A. mellifera, was expressed in a dose-dependent manner. Bees were challenged with injection of the indicated dosages of freeze-dried bacterial, prepared in water, then nodulation was recorded at 4-h PI. Each point indicates the mean number of nodules found in each insect ( $n=6$ individuals), and the error bars represent 1 S.E.M.

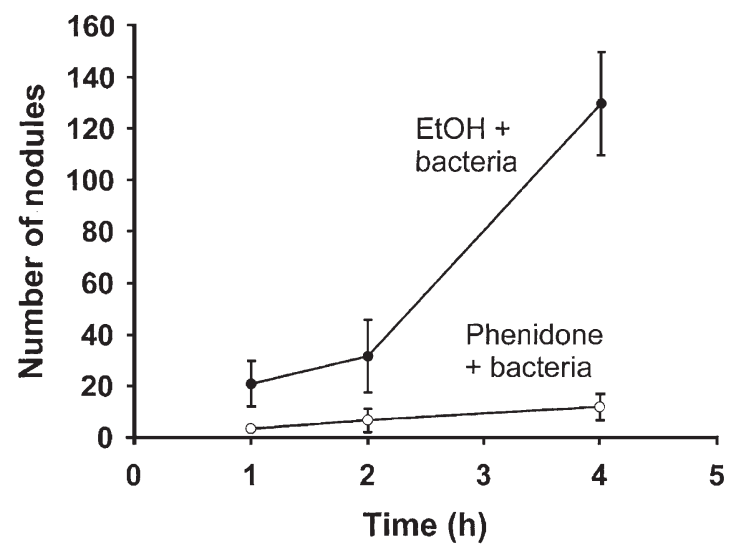

Figure 3. Time course of nodulation in adult honey bees, $A$. mellifera, in response to intrahemocoelic challenge with freezedried pathogenic bacterium, S. marcescens. Control insects were first treated with ethanol, then injected with bacteria and experimental insects were first treated with phenidone, then injected with bacteria. Each point indicates the mean number of nodules found at the indicated times PI in each insect $(n=5$ or 6 individuals), and the error bars represent 1 S.E.M.

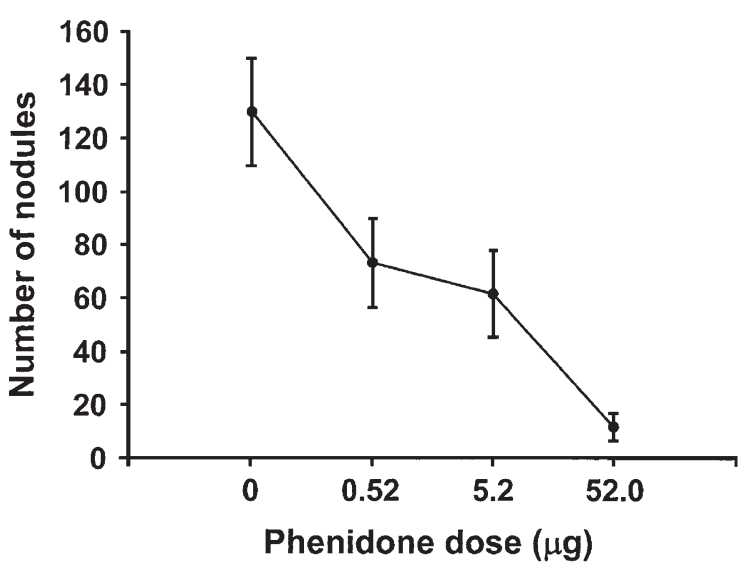

Figure 4. Dose-response curve for the influence of phenidone on nodule formation in adult honey bees. Individuals in four groups of bees were first treated with indicated dosages of phenidone, then challenged with intrahemoceolic injections of freeze-dried bacteria, S. marcescens. Nodulation was assessed at 4-h PI. Each point indicates the mean number of nodules found in each insect $(n=6)$ and the error bars represent 1 S.E.M.

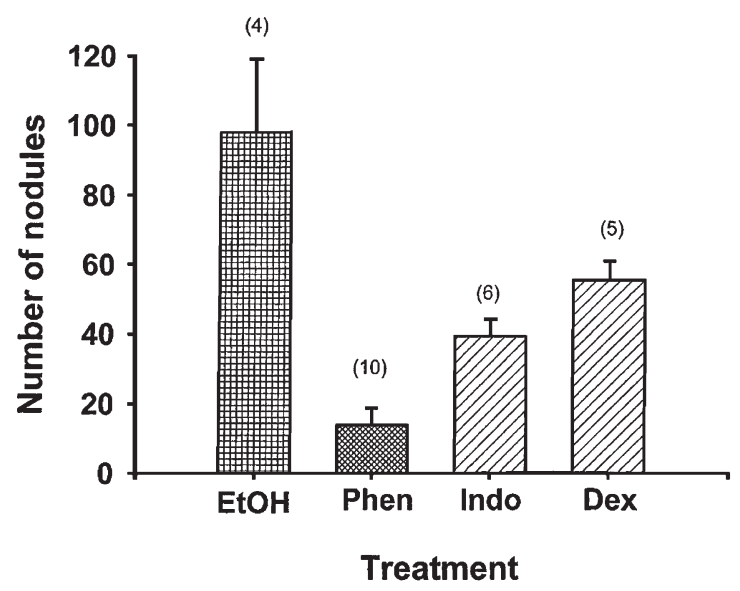

Figure 5. Effect of treating honey bees with individual eicosanoid biosynthesis inhibitors on nodule formation in response to intrahemocoelic infections with the insect pathogen, S. marcescens. Test insects were first injected with $52 \mu \mathrm{g}$ of either dexamethasone (Dex, $\mathrm{PLA}_{2}$ inhibitor), indomethacin (Indo, cyclooxygenase inhibitor) or phenidone (phen, dual cyclooxygenase/lipoxygenase inhibitor), then challenged with intrahemocoelic injections of freeze-dried bacteria, S. marscescens. Control insects were first injected with ethanol (EtOH), then similarly challenged. Nodulation was assessed at 4-h PI. The height of the histogram bars represents the mean number of nodules found in each insect and the error bars represent 1 S.E.M. The number in parentheses represents the number of individuals in each treatment. Histogram bars with the same fill pattern are not significantly different from each other (LSD, $P<0.01)$. 


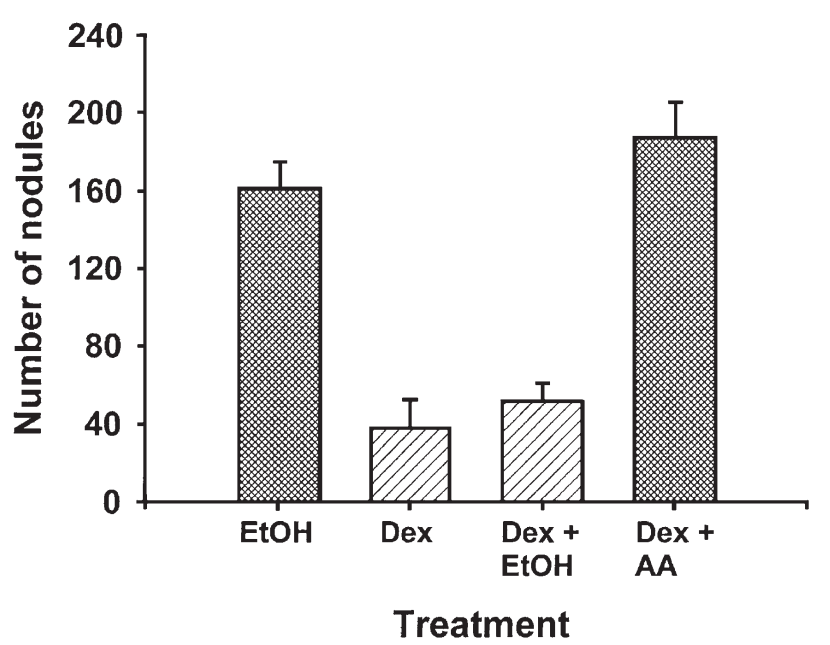

Figure 6. The eicosanoid-precursor fatty acid, arachidonate, reversed the effect of dexamethasone on nodulation in adults of A. mellifera. Honey bees were treated with ethanol (EtOH) or dexamethasone (Dex) and then challenged with intrahemocoelic injections of freeze-dried bacteria, S. marcescens. Immediately after challenge, test insects were treated with $20 \mu \mathrm{g}$ of arachidonic acid (Dex+AA). Control insects were treated with dexamethasone and ethanol (Dex+EtOH). The height of histogram bars represents the mean number of nodules found at 4$h$ PI in each insect ( $n=6$ individuals) and the error bars represent 1 S.E.M. Histogram bars with the same fill pattern are not significantly different from each other (LSD, $P<0.01$ ).

\subsection{Eicosanoid biosynthesis by abdominal tissues}

The gut-free bodies of newly-emerged adult honey bees converted arachidonic acid into two prostaglandins, $\mathrm{PGA}_{2}(1.05 \mathrm{pmol} / \mathrm{mg}$ protein $/ \mathrm{h})$ and $\mathrm{PGF}_{2 \alpha}$ $(0.07 \mathrm{pmol} / \mathrm{mg}$ protein $/ \mathrm{h})$. As seen in many insect preparations, $\mathrm{PGA}_{2}$ appears to be the predominant product.

\section{Discussion}

In this paper we report on the outcomes of experiments designed to test the eicosanoid hypothesis in adults of the honey bee, Apis mellifera. The results of all experiments support the hypothesis for newlyemerged, but not for foraging bees. First, treating experimental bees with phenidone prior to challenging them with freeze-dried bacterial preparations significantly reduced nodulation at all points in the time course experiments. Second, the influence of phenidone on nodulation was expressed in a dose-dependent manner. Third, three different eicosanoid biosynthesis inhibitors significantly reduced nodulation relative to control treatments. Fourth, the influence of dexamethasone on nodulation was reversed by treating infected bees with arachidonic acid. Finally, we found that gut-free tissue homogenates were able to convert arachidonic acid into two prostaglandins. This indicates that honey bee tissues express the enzymes required for eicosanoid biosynthesis. Taken together, these separate lines of evidence strongly support the overall hypothesis.

The results of the time course experiment indicate that bees treated with phenidone produced significantly fewer nodules than the control bees at all time points in the experiment. We infer from this finding that inhibition of eicosanoid biosynthesis influences the cellular events involved in nodulation early in the infection process, and continues to exert a negative influence for many hours PI.

The time course experiment also indicates the upper limits of nodulation reactions to bacterial infections in bees. The experimental honey bees produced a maximum of approximately 130 nodules/individual by 4 -h PI. This value is in line with the outcomes of similar experiments with other insect species. Larvae of the tenebrionid beetle, Z. atratus produced approximately 50 nodules/individual at 6 -h after infection with the same number of bacterial cells (Miller et al., 1996). The larvae of several Lepidoptera produced more nodules in response to similar challenges. Tobacco hornworms, $M$. sexta yielded approximately 120 nodules/individual by 6-h PI (Miller et al., 1994), and silkworms, B. mori, formed approximately 80 nodules/individual at 15-h PI (Stanley-Samuelson et al., 1997). In our work with another hemimetabolous species, Miller et al. (1999) recorded approximately 45 nodules at 4-h PI in identical experiments with adult crickets, G. assimilis.

Howard et al. (1998) suggested that differences in nodulation intensity might be due to differences in circulating hemocyte populations. In work with tobacco hornworms and larvae of Z. atratus, Howard et al. (1998) recorded numbers of nodules formed in reaction to similar bacterial challenges as a function of insect size, weight and age. These experiments showed that nodulation was not influenced by these three parameters. Noting that insects tend to maintain fairly similar concentrations of circulating hemocytes (approximately $4-6 \times 10^{6}$ cell $/ \mathrm{ml}$ hemolymph), those insect species with copious amounts of hemolymph, such as tobacco hornworms, would have far larger absolute numbers of circulating he- 
mocytes. The authors speculated that if circulating hemocyte population sizes account for differences in nodulation capacity, then, it should not be surprising to record considerable differences among insect species in nodulation responses to similar infection challenges.

These comments are germane to our finding that older, foraging honey bees did not form visible nodules in reaction to bacterial challenge. We were unable to prepare hemolymph samples from foragers, even at the $\mu$ l scale, from which we inferred that older honey bees have very few circulating hemocytes. The very low, for practical purposes, absent volumes of collectable hemolymph, with attendant low populations of circulating hemocytes, may be a form of immune senescence. Honey bees go through a lengthy excursion of age-related tasks, beginning with in-hive tasks such as tending brood and comb building and ending with outside tasks, including ventilating and finally foraging. While newly-emerged and cell-cleaning bees do not overlap in age with foragers, there is considerable overlap in age-related task performance (Winston, 1987). The mean age at first foraging is approximately 23 days, ranging from 18 to 28 days, which overlaps the age of several advanced in-hive tasks. Immune senescence may occur in honey bees, however, until this is investigated in more detail, it cannot be said whether the phenomenon is linked to physiological age or the onset of a certain category of tasks, such as outside tasks.

We considered influence of phenidone dosage on nodulation reactions to similar bacterial challenges. Dose-response relationships are basic to physiological research, and the approximately linear negative relationship we obtained for phenidone strongly supports the idea that eicosanoids mediate nodulation reactions to bacterial infections in the honey bee.

Due to their importance in human medicine, many different inhibitors of eicosanoid biosynthesis are available. Some, such as aspirin and ibuprofen, are available as analgesic drugs for relief of minor pains, while many others are not yet approved for use in humans. These compounds, which we refer to with the general term 'eicosanoid biosynthesis inhibitors', exert different actions in cellular eicosanoid biosynthesis. For example, dexamethasone inhibits PLA ${ }_{2}$. Dexamethasone exerts other actions, as well, including influence on gene expression. Several compounds specifically inhibit cyclooxygenase, the first step in prostaglandin biosynthesis (Figure 1). Our experi- ments with different inhibitors showed that all three of the compounds we tested resulted in similar reductions in nodulation. The observation that separate experiments with different inhibitors of eicosanoid biosynthetic pathways similarly retarded nodulation in adult honey bees indicate that eicosanoids act in nodule formation.

The results of the rescue experiments strongly support our hypothesis that eicosanoids mediate nodulation in honey bees. Dexamethasone is thought to act by inhibiting $\mathrm{PLA}_{2}$, the enzyme responsible for releasing arachidonic acid from cellular phospholipids. This is the first and rate-limiting step in eicosanoid biosynthesis. Dexamethasone inhibits eicosanoid biosynthesis by inhibiting the release of substrate from cellular phospholipids, which in effect withholds substrate from cyclooxygenase and other eicosanoid biosynthesizing enzymes. If this is so, then providing arachidonic acid to the immunity-conferring cells within the honey bees would be expected to reverse the influence of dexamethasone on nodulation. Indeed, the arachidonic acid treatments restored the honey bees' ability to produce nodules in response to bacterial infections.

Stanley-Samuelson (1994) indicated that experiments with eicosanoid biosynthesis inhibitors were based, in part, on the assumption that the experimental insects were competent to biosynthesize eicosanoids. The presence of eicosanoid precursor polyunsaturated fatty acids and the enzymes responsible for eicosanoid biosynthesis have been documented for honey bees ( Stanley-Samuelson and Dadd, 1983). In this paper, we document the presence of eicosanoid biosynthesizing enzymes in fat body of adult honey bees. The honey bee preparations yielded $\mathrm{PGA}_{2}$ (at approx. $1.05 \mathrm{pmol} / \mathrm{mg}$ protein/h) as the major product. Rates of prostaglandin biosynthesis recorded from in vitro insect preparations are typically low, and the values recorded with honey bee preparations are similar to values recorded from larvae of the butterfly, Colias eurytheme (Stanley-Samuelson et al., 1997) and adults of cicadas, Magicicada septendecim (Tunaz et al., 1999). Hence, a basic assumption of this line of experimentation has been met.

Our background control experiments indicate that the nodules we recorded were due to the experimental treatments, and not to adventitious infections. Honey bees taken directly from the colony had a low background of nodulation. The injec- 
tion treatments, similarly, did not influence the low background of nodulation. We note that control experiments with ethanol yielded higher numbers of nodules than recorded with other insect species (Miller et al., 1994, 1996), however, the key point is that the drug vehicle did not, in itself, diminish the bees' ability to form nodules. We note that control treatments with phenidone in the vehicle yielded very few nodules, indicating that the ethanol-induced nodulation also is mediated by eicosanoids. We infer that the experimental protocols allow a physiological interpretation of the data, inhibition of eicosanoid biosynthesis impairs immunity in newly-emerged honey bees.

\section{Acknowledgments}

Thanks to Dr. R. W. Howard (USDA/ARS, Manhattan, KS) and Dr. Juan Cibrian for a critical reading of a draft of this paper. This is paper no. 13 359, Nebraska Agricultural Research Division and contribution no. 1105 of the Department of Entomology. This work was supported by a fellowship from KahramanMaras Sutcu University to H. Tunaz and by the Agricultural Research Division, University of Nebraska (NEB 17-054).

\section{References}

Dunn, 19904 P. E. Dunn, Humoral immunity in insects: Immune strategy appears to correspond to life-history characteristics. BioScience 40 (1990), pp. 738-744.

Gupta, 1991 A. P. Gupta, editor, Immunology of Insects and other Arthropods, CRC Press, Boca Raton, FL (1991), p. 495.

Horohov and Dunn, 19834 D. W. Horohov and P. E. Dunn, Phagocytosis and nodule formation by hemocytes of Manduca sexta following injection of Pseudomonas aeruginosa. J. Invertebr. Pathol. 41 (1983), pp. 203-213.

Howard and Stanley, 19994 R. W. Howard and D. W. Stanley, The tie that binds: Eicosanoids in invertebrate biology. Ann. Entomol. Soc. Am. 92 (1999), pp. 880-890.

Howard et al., $1998<$ R. W. Howard, J. S. Miller, and D. W. Stanley, The influence of bacterial species and intensity of infections on nodule formation in insects. J. Insect Physiol. 44 (1998), pp. 157-164.

Jurenka et al., $1997 \varangle$ R. A. Jurenka, J. S. Miller, V. K. Pedibhotla, R. L. Rana, and D. W. Stanley-Samuelson, Eicosanoids mediate microaggregation and nodulation responses to bacterial infections in black cutworms,
Agrotis ipsilon, and true armyworms, Pseudaletia unipuncta. J. Insect Physiol. 43 (1997), pp. 125-133.

Mandato et al., $1997 \varangle$ C. A. Mandato, W. L. Diehl-Jones, S. J. Moore, and R. G. H. Downer, The effects of eicosanoid biosynthesis inhibitors on prophenoloxidase activation, phagocytosis and cell spreading in Galleria mellonella. J. Insect Physiol. 43 (1997), pp. 1-8.

Miller and Stanley, $1998<$ J. S. Miller and D. W. Stanley, The nodule formation reaction to bacterial infection: assessing the role of eicosanoids. In A. Wiesner et al., Techniques in Insect Immunity, SOS publications, Fair Haven, NJ (1998), pp. 265-270.

Miller et al., 1994 J. S. Miller, T. Nguyen, and D. W. Stanley-Samuelson, Eicosanoids mediate insect nodulation responses to bacterial infections. Proc. Nat. Acad. Sci. USA 91 (1994), pp. 12418-12422.

Miller et al., 1996 J. S. Miller, R. W. Howard, T. Nguyen, A. Nguyen, R. M. T. Rosario, and D. W. Stanley-Samuelson, Eicosanoids mediate nodulation responses to bacterial infections in larvae of the tenebrionid beetle, Zophobas atratus. J. Insect Physiol. 42 (1996), pp. 3-12.

Miller et al., 19994 J. S. Miller, R. W. Howard, R. L. Rana, H. Tunaz, and D. W. Stanley, Eicosanoids mediate nodulation reactions in adults of the cricket, Gryllus assimilis. J. Insect Physiol. 45 (1999), pp. 75-83.

SAS Institute Inc., 1989 SAS Institute Inc. 1989. SAS/ STAT® User's Guide, Version 6, 4th edition, vol 2, SAS Institute Inc., Cary, NC.

Stanley, $2000 \triangleleft$ D. W. Stanley Eicosanoids in Invertebrate Signal Transduction Systems, Princeton University Press, Princeton, NJ (2000) p. 292.

Stanley and Howard, 1998 D. W. Stanley and R. W. Howard, The biology of prostaglandins and related eicosanoids in invertebrates: Cellular, organismal and ecological actions. Am. Zool. 38 (1998), pp. 369-381.

Stanley-Samuelson, 1994 D. W. Stanley-Samuelson, Assessing the significance of prostaglandins and other eicosanoids in insect physiology. J. Insect Physiol. 40 (1994), pp. 3-11.

Stanley-Samuelson and Dadd, $1983<$ D. W. Stanley-Samuelson and R. H. Dadd, Long-chain polyunsaturated fatty acids: Patterns of occurrence in insects. Insect Biochem. 13 (1983), pp. 549-558.

Stanley-Samuelson and Ogg, $1994<$ D. W. Stanley-Samuelson and C. L. Ogg, Prostaglandin biosynthesis by fat body from the tobacco hornworm, Manduca sexta. Insect Biochem. Molec. Biol. 24 (1994), pp. 481-491.

Stanley-Samuelson et al., $1991<$ D. W. Stanley-Samuelson, E. Jensen, K. W. Nickerson, K. Tiebel, C. L. Ogg, and R. W. Howard, Insect immune response to bacterial infection is mediated by eicosanoids. Proc. Natl. Acad. Sci. USA 88 (1991), pp. 1064-1068. 
Stanley-Samuelson et al., 1997 D. W. Stanley-Samuelson, V. K. Pedibhotla, R. L. Rana, A. R. Nor Aliza, W. W. Hoback, and J. S. Miller, Eicosanoids mediate nodulation responses to bacterial infections in larvae of the silkmoth, Bombyx mori. Comp. Biochem. Physiol. 118A (1997), pp. 93-100.

Tunaz and Stanley, 19994 H. Tunaz and D. W. Stanley, Eicosanoids mediate nodulation reactions to bacterial infection in adults of the American cockroach, Periplaneta americana (L.). Proc. Entomol. Soc. Ont. 130 (1999), pp. 97-108.
Tunaz et al., 19994 H. Tunaz, J. C. Bedick, J. S. Miller, W. W. Hoback, R. L. Rana, and D. W. Stanley, Eicosanoids mediate nodulation reactions to bacterial infections in adults of two 17-year periodical cicadas, Magicicada septendecim and M. cassini. J. Insect Physiol. 45 (1999), pp. 923-931.

Winston, $19874 \mathrm{M}$. L. Winston The Biology of the Honey Bee, Harvard University Press, Cambridge, MA (1987) p. 281 . 